Article

\title{
Public-Private Partnerships and Sustainable Agricultural Development
}

\section{Marco Ferroni * and Paul Castle}

Syngenta Foundation for Sustainable Agriculture, Schwarzwaldallee 215, 4058 Basel, Switzerland; E-Mail: paul.castle@syngenta.com

* Author to whom correspondence should be addressed; E-Mail: Marco.ferroni@ syngenta.com; Tel.: +41-61-323-6938; Fax: +41-61-323-7200.

Received: 1 July 2011 / Accepted: 12 July 2011 / Published: 20 July 2011

\begin{abstract}
Agriculture in Africa is not sustainable because average yields have been stagnating for decades due to underinvestment, especially in the development of agricultural markets, crop improvement and the sustainable management of agricultural systems. Low public sector funding for agricultural research and lack of incentives for the private sector to operate in areas where there is no market largely explain the yield gap in many food-importing developing countries. Yet, there are effective ways in which the public and the private sector could work together and jointly improve agricultural sustainability in poor countries. The public sector provides a favorable institutional environment for the development of agricultural markets and investment in rural infrastructure, facilitates local business development and funds research with local relevance. The private sector, in return, brings its considerable expertise in product development and deployment. This article illustrates how new forms of public-private partnerships (PPPs) for agricultural development can work in challenging environments. It discusses three promising examples of PPPs in which the Syngenta Foundation for Sustainable Agriculture (SFSA) is actively involved, and shows that an experimental approach can sometimes be more effective than social planning in efforts to achieve sustainable agriculture.
\end{abstract}

Keywords: sustainable agriculture; public-private partnerships; synergies; guidelines 


\section{Introduction}

Agriculture made great progress during the "Green Revolution" of the 1960s and 1970s. Companies and public sector organizations around the world continue to achieve breakthroughs in many areas that contribute to global food security. Nonetheless, yields in key crops still vary significantly between farming regions, and often remain far below their optimal potential. Crop losses pre- and post-harvest continue to prevent an estimated 40 percent of agricultural produce from actually reaching the marketplace [1]. There are many reasons for these shortfalls, but one frequent cause is farmers' lack of access to technology, adequate extension services and poor market integration.

There are two main reasons for "lack of access" to a particular technology: either it has not yet been developed, or it actually exists, but is not yet available everywhere it is demanded. There are still numerous pests, diseases and other agricultural challenges for which no proper solution is available at all. There are also many solutions of which scientists are aware, but which are not yet deployed commercially in all the settings in which they could help. Both kinds of "lack of access" hold farmers back around the world, but particularly in developing countries.

Traditionally, the public and private sector have attempted to provide solutions independently from each other, with the exception of certain sections in the long path from basic research to widespread commercial deployment where collaboration was unavoidable. It has been argued, for example, that the "Green Revolution" was a public sector initiative that partially crowded out private activities and thus resulted in a general neglect of tailor-made solutions for farmers [2]. Isolated approaches are therefore unable to cope with challenges of the 21 st century, notably the achievement of the farmingrelated Millennium Development Goals. The first main section of this article illustrates the effectiveness of public-private partnerships (PPPs) by means of three selected examples and draws some general lessons for future PPPs.

PPPs are a popular type of collaboration in many sectors of the economy around the world. In one form or another, partnerships between public institutions and private individuals or organizations have existed for centuries. Medieval church-building is arguably one example; in the 19th century, universities in the USA and Germany played a key role in facilitating their countries' industrialization [3]. Modern examples continue to include tertiary education, as well as such diverse areas as infrastructure, defense, pharmaceuticals, road management and the Olympics. There is also a growing realization of the value of PPP in agriculture, and particularly for projects that benefit farmers in developing countries. So far, however, very few agricultural PPPs exist. Those that do are largely experimental, and form a new field of practice and inquiry for the participants.

PPPs can take a variety of forms. They are not limited to bilateral collaboration between a government agency and a private corporation. PPP for sustainable agricultural development can also include, for example, multi-partner structures that bring together private companies with entities such as non-governmental organizations (NGO), university research institutes and foundations. These structures have sometimes been termed "Hybrid Value Chains" that create shared value [4]. The present article uses the term "PPP" broadly, to include both these forms and the many other possible for-profit/not-for-profit combinations.

Whatever form they take, successful PPPs have a number of features in common. The rationale for their creation is always the same: to achieve more through partnership than any of the parties could do 
on their own [5]. A PPP in agricultural research and development (R\&D), for example, can overcome both the public sector's usually limited ability to take research outputs to market, and the private sector's limited scope for operation where there is no commercially viable market. Contracts, planning, inter-partner relationships and the distribution of tasks within the PPP should all contribute to maximizing synergies between the parties involved.

\section{Agricultural Public-Private Partnerships in Current Practice}

The June 2010 "G-20" Summit in Toronto, Canada, stressed that "there is still an urgency to accelerate research and development to close agricultural productivity gaps". The meeting went on to declare that "the private sector will be critical in the development and deployment of innovative solutions that provide concrete results on the ground" [6].

G-20 governments are certainly right to stress the key role of the private sector here. Growth in public investment in productivity-enhancing agricultural R\&D has been declining for some time in most of the world outside China, and total investment has declined in critical regions such as Sub-Saharan Africa [7]. Private investments and capability, on the other hand, continue to grow [8]. This must, however, not mislead observers into thinking that the private sector should-or even could-address the huge challenge of helping farmers achieve sustainable food security on their own. R\&D partnerships are instead necessary to pool public and private assets. Private organizations contribute expertise in plant sciences, genomics and bioinformatics, for example. The public sector provides strength in crop improvement, and is generally more likely than private companies to commit research resources to "orphan" crops. The international Tef Improvement Project is used as an example later on to illustrate how that might work in practice [9].

Importantly, the contribution of the private sector to agricultural development goes far beyond research. It is in the nature of for-profit enterprises to bring products to the market and deliver value, including to smallholders. Driven by the need to commercialize new technologies, companies also have considerable expertise in product development, marketing and delivery. Public programs in agricultural R\&D have been successful in certain important areas. However, they are frequently ineffective when it comes to actually delivering products such as improved seed varieties that are tailored to the farmer's actual needs, and thus to facilitating repeat purchase and effective use. Public sector incentives can be helpful in the introductory phase of new hybrid seeds, but these should definitely not be made available free of charge. Well-meaning but over-generous government hand-outs stifle private initiatives, and raise inappropriate long-term expectations among farmers.

The private sector goes only where there is a commercial incentive. Farmers too remote or too poor to purchase inputs do not benefit from innovations. In fact, the technologies they need may not even get developed. PPPs offer the prospect of overcoming each sector's limitations: the business sector's inherent inability to operate where there is no market, and the public sector's limited ability to market research outputs. Put more positively: partnerships enable sustainable outcomes that no single party could achieve alone. Ideally, a PPP's output is more than the sum of its parts.

Deployment of products in marginal rural areas is vital. Global food security depends heavily on smallholders in such areas. There is a great potential to better connect markets, services and technologies and thus increase their productivity. Based on agricultural censuses, the Syngenta 
Foundation for Sustainable Agriculture (SFSA) estimates that non-OECD countries have approximately 450 million small farm units [10], defined here as "up to two hectares". Assuming an average household of five, this means that about one-third of the world's population directly depends on small-scale farming for at least part of its livelihood. Smallholders produce a large share of the food consumed in developing countries and emerging markets. Their ability to earn incomes from farming and in turn pay for inputs, consumer goods, and, for example, school fees for their children, also affects general development prospects and economic transformation.

The following three examples illustrate how PPPs add more value to small-scale farmers and how such partnerships allow them to cope better with uncertainty. The first two examples involve the use of non-transgenic agricultural biotechnology to improve crop yields and the last one shows how marketand weather-related uncertainties can be addressed through micro-insurance schemes.

\subsection{Non-Profit Partnership: Smaller Tef Plants}

Tef (Eragrostis tef, from the sorghum/millet family) is an African "orphan" crop, meaning that it has not been the subject of much research and development work due to its limited international commercial potential. Tef is the most widely cultivated cereal in Ethiopia, where about $85 \%$ of the population lives in rural areas [11]. The plant is excellently adapted to the climatic and soil conditions in Ethiopia, where it performs better than other cereals in both drought and water-logged conditions. The seeds contain high protein levels and are free of gluten, to which millions of people worldwide are allergic [12]. However, the average tef yield is much lower than for most other cereals. "Lodging" is the major problem: tef has a tall, tender stem which easily falls over under the weight of the seed head.

The SFSA is now working with the University of Berne, Switzerland, to develop shorter "semi-dwarf" plants. In the past, conventional breeding of tef did not generate significant genetic improvements. To address this challenge, the team in Berne, led by an Ethiopian researcher, is using a

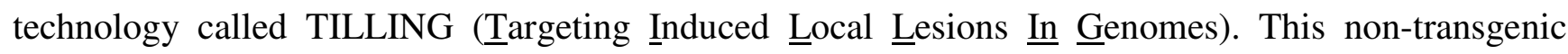
method is designed to identify and introduce hereditable variation in genes that affect the relevant growth traits [9]. The Berne team has transferred its findings with tef to a public scientific center in Kenya for implementation, and field-testing has begun in Ethiopia.

\subsection{Profit/Non-Profit Partnership: Rust-Resistant Wheat}

The tef project is an example of a partnership involving various types of non-profit partners. The wide range of agricultural challenges is also being met by "classical" public-private collaborations involving a for-profit partner. In 2009, for example, the SFSA brokered a two-year public-private partnership focusing on wheat. The partners aim rapidly to identify and map genetic markers for use in breeding resistance to Ug99 stem rust. According to the FAO, wheat has recently become the world's second most important food crop [13]. It provides 500 kilocalories of food energy per capita per day in China and India, and can deliver up to 50 percent of daily calorie uptake in Central and West Asia and North Africa [14].

Ug99 is caused by the fungus Puccinia graminis, and can cause devastating crop losses. The disease first emerged in Uganda in 1999, and is currently spreading across Africa, Asia and the Middle East. It has the potential to move much further, posing a serious risk to the world's wheat supplies. Even 
without the threat of $\mathrm{Ug} 99$, wheat yields need to rise by an estimated 1.6 percent each year to reach required global production levels by 2020 [15], yet investments in wheat technology have lagged far behind those for other major cereals. The SFSA project combines private sector plant genetic profiling expertise with public sector strengths in field research. The results will contribute directly to worldwide efforts to combat stem rust, coordinated by the Borlaug Global Rust Initiative.

\subsection{Multi-Partner Collaborations: Biofortification}

The SFSA also supports the HarvestPlus Challenge Program to improve global nutrition. The partners aim to make staple food crops rich in important nutrients available. HarvestPlus, an initiative of the Consultative Group on International Agricultural Research (CGIAR), is an interdisciplinary global alliance of research institutions and implementing agencies. HarvestPlus focuses on improving the nutritional value of staple foods that poor people already eat. This "biofortification" uses conventional breeding to develop crops richer in necessary minerals and vitamins. The aim is to deliver micronutrients cost-effectively and sustainably to malnourished populations, especially in rural areas. Work includes developing plant breeding tools, crossing and testing crop lines for nutritional effects, disseminating new varieties, and measuring their effectiveness in improving malnutrition.

The current development phase focuses on three micronutrients in six crops across seven Asian and African countries. The program has already released one crop: an orange-colored sweet potato rich in vitamin A and now available in Uganda and Mozambique. The main emphasis is now on iron in pearl millet (India) and bean (Rwanda), as well as on vitamin A in hybrid corn (Zambia) and cassava (Nigeria). Along with the SFSA, the program's international supporters include much larger organizations such as the Gates Foundation, USAID, the World Bank and the UK's Department for International Development. The HarvestPlus development phase is intended to run until 2013, with delivery and impact measurement thereafter.

\subsection{Multi-Partner Collaborations: Information Technology for Agricultural Development}

As stressed above, PPP for sustainable agriculture can and must go beyond R\&D cooperation. They can also be a central ingredient in the creation or stimulation of markets that benefit smallholders, whether on the input or output side. Micro-insurance provides an example.

One of the many constraints affecting agriculture in developing countries is smallholders' very understandable aversion to risk, which affects their willingness to invest in better seed and fertilizer. In Kenya, for example, only about half the farmers buy improved seed or other inputs [16]. Many use poor-quality seed from previous harvests. This is because drought or flooding can easily destroy their crops and wipe out the benefits of purchased inputs. The result of not using the best inputs, however, is that yields remain far below their potential. To overcome this problem, the SFSA has launched a multi-partner Agriculture Index Insurance Initiative. Its aim is to explore and develop the potential of micro-insurance for smallholders. The insurance is branded as Kilimo Salama (KS), which means 'safe farming' in Kiswahili. Insurance should be simple, affordable and relevant to small farmers. With KS, smallholders can insure selected farm inputs at their local retailer and pay half the premium. To make the insurance affordable, the initiative's agribusiness participants pay the other half. 
Mobile phone technology is very widely used in rural Kenya. In the KS scheme, stockists use a camera-phone to scan a bar code on each insured input. A text message confirming the policy instantly goes to the farmer's cell phone. To monitor the insurance, the SFSA has set up automated weather stations. If a station reports at the end of the season that local rainfall has been insufficient, farmers in the affected area receive a payout. This operates via a money transfer service run by the initiative's telecommunications partner. Using weather station data rather than personal field assessment further contributes to keeping the cost of insurance low, and thus within farmers' reach. Payout via phones avoids problems with middlemen or cash transport to remote areas. Uptake of KS insurance expanded rapidly, from 200 smallholders in the 2009 pilot phase to almost 12,000 in 2010. No single party in the PPP could have achieved this result alone. Nor, indeed, could any two of the many partners.

These are a few of the promising or already successfully concluded examples of inter-sector partnerships in agricultural development. Overall, PPPs currently remain a greatly underused option in the range of solutions available to tackle the challenges of enhancing smallholder productivity and livelihoods. This is as true in relation to agricultural biotechnology as it is in other areas. What, therefore, should parties who believe that a PPP could be the right choice for solving a particular problem bear in mind during the first steps towards successful partnership?

\section{Advice to Organizations Planning a PPP for the First Time}

Many decision-makers in both for-profit and not-for-profit organizations still prefer to shy away from even inexpensive short-term collaboration with other sectors. Sometimes this may simply result from lack of knowledge of "how the other half works"; sometimes it stems from awareness of partnerships that have failed. However, as the four current PPP examples above, and others already completed, continue to demonstrate, the efforts involved can bring considerable benefits.

The SFSA has been involved in PPP for a decade, and its predecessor foundations have been involved for much longer. The following guidelines are drawn from our overall experience, and vary in importance from case to case. Taken together, however, observation of these guidelines significantly increases potential partners' chances of coming together, and then of taking their joint project through to successful conclusion. These rules of conduct hold true for every form of PPP, and are mostly not limited to the area of agricultural development. The present article concentrates on four key pillars: initial partnering, priority-setting, contractual arrangements, and transparency. Each of these areas covers a wide range of points, which cannot all be discussed exhaustively here, but on which extensive guidance is available elsewhere [17,18]. There are also a number of further inter-linking topics which require special care when creating PPP. These include areas as varied as intellectual property (for example, but by no means exclusively, in the area of genetic modification), business plans, accountability and external communication. In the particular area of agricultural development PPP, questions of stewardship and liability also demand careful attention.

The choice of suitable partner or partners should be taken very seriously. The aim is to compose a PPP with a maximum of complementary skills and resources likely to generate the greatest possible output. Selection must therefore start with a realistic assessment of one's own strengths and weaknesses. It is then essential to invest considerable research in identifying organizations most likely to benefit from and add to this profile. However, finding a particular skill set is not enough on its own: 
the relevant organization must be willing, as well as able. Willingness has many components, some of which take time to discover or develop. It is often easiest to determine the degree to which organizations' goals and vision match each other. For example: a project that solely benefits Tanzanian smallholders rather than large-scale farming operations in Iowa may not fully address every private company's commercial growth aspirations.

Where current goals clearly do match, it can still be difficult to assess long-term commitment to them, and to a possible PPP. This is especially true if there are set-backs along the way, or if a party believes the benefits to be unfairly distributed. Establishing the range and depth of benefits and their balance between parties face-to-face is vital. There need to be real benefits for everybody involved. Also essential for cooperation, but usually achieved only through considerable efforts over time, is mutual trust. Throughout the process of partner identification, frank and honest assessment of motivation is additionally crucial: Does a particular organization genuinely wish to be a good partner over the next few years, or is it only really interested in speedy access to something that it does not currently possess?

With the initial selection made, and first personal contacts developing, the time has come for priority setting. It is vital that all potential partners are open about where they see the priorities in the intended joint project. This discussion should include not only the desired main goals and milestones within the project, and the order in which they are to be tackled, but also its position on each organization's own internal priority list. The relevant statements all require careful documentation. Each partner's ability to make the success of the joint project a high priority within its own organization is also very important. Each party needs high-ranking sponsors of the PPP, and should make work on the project an explicit part of key employees' job descriptions and/or rolling annual achievement targets. Parties should openly discuss the similarities and differences in their operational culture and values. These are easy to dismiss as "not scientifically or financially important", but they can profoundly affect a partnership's productivity.

Whatever their differences in organizational culture, participants in successful PPP repeatedly emphasize the vital importance of clear and detailed contracts. Particularly in intercontinental collaborations, where personal meetings are infrequent, and teleconferences rarely a full substitute, the written word plays a central role in shaping project progress. Contracts must, among other matters, unambiguously determine the division of tasks, and the distribution and use of any commercial rights emerging in connection with the project. Topics such as liability and intellectual property also require careful attention. When drafting a contract, parties are encouraged to build on the progress made during their initial meetings. The contract draft must reflect the principles already agreed. Legal departments often like to start with a standard template instead, but this can be very counterproductive.

Partners must also discuss any major "blockers" as early as possible. An example of such a brake on collaboration could be an existing contractual arrangement between one of the PPP parties and another organization outside the new partnership. Discussions about such blockers usually require additional management, business or legal representatives. Early involvement of intellectual property and legal experts enables top managers to understand any potentially non-negotiable assumptions before they progress too far with discussions. Exclusivity, commercial exploitation and confidentiality are common hurdles in this area. A formal signed Memorandum of Understanding (MoU) between the parties can be very helpful in setting the framework for negotiations. The MoU needs to contain the 
fundamental points of principle that will underpin the PPP and encourage operational problem-solving. One key assumption needs to be that each PPP will have an individual identity and contain unique elements. Negotiations should therefore run case by case, and parties must allocate resources accordingly. Realism about the necessary timeframes is important here: parties frequently have widely differing internal processes, often simply as a result of their size. Each organization needs to respect partners' ways of working. Creating realistic expectations about the time needed for responses to proposals will help prevent frustration.

A fourth pillar of PPP success is transparency. Partners need to understand and respect each other's communication requirements. This is true not only for privacy and institutional competitiveness, but also for scientific information-sharing amongst public sector researchers, public awareness-building about new technology and products, fulfillment of public reporting obligations, and aspects such as publication of student theses. Open communication does not always come naturally to private organizations, particularly with regard to research results. The private sector generally maintains a culture of privacy in $R \& D$, in order to be first to the patent office and/or gain all the advantages of leading into a new market. Private sector interest is usually closely linked to commercialization rights, which need to be explicitly defined at the start of a PPP. Private companies mostly aim to retain free access to their knowledge, which has been expensive to generate. They also want to prevent its use by competitors. This tendency to privacy is not restricted to well-established multinational corporations: for example, university spin-offs typically also seek to maintain confidentiality. In this context, policy incentives that help the private sector to cope better with uncertainty and push the cost-benefit calculation of PPPs more toward expected benefits can help overcome initial concerns and facilitate collective action at more favorable terms.

In a PPP, ensuring full transparency and yet enabling collaborators to keep some competitive advantage from privileged knowledge is a recurring challenge. Public sector parties are not always comfortable with this aspect of deal-making, and may wish to postpone discussions until more trust and understanding have been established. Experience suggests, however, that it is better to agree on the fundamentals of commercial rights and transparency before investing a lot of time and money in other aspects of the PPP.

\section{Conclusions}

In conclusion, it is worth recalling a number of points about PPPs. Firstly, their usefulness is by no means limited to agricultural development, but they can make a major contribution in this area. PPPs are not automatically the right choice to solve every challenge in agriculture: the private sector is certainly able to improve fungicide spray nozzles without involving government researchers, and the public sector does not usually need corporate guidance on the establishment of crop germplasm collections. However, where the right partners come together in the right way, the synergies they achieve can lead to results well beyond the reach of any one organization alone. Extensive guidance is available to those embarking on a PPP for the first time. It should, however, also be remembered that every PPP is an experiment - a new mixture of partners, needs, technologies, goals and intended beneficiaries. Open-mindedness and a willingness to learn are therefore always essential. PPPs still 
have considerable scope for expansion, and merit much more frequent consideration in agriculture than they have enjoyed hitherto.

\section{Acknowledgements}

Ferroni and Castle would like to acknowledge the assistance of Viv Anthony and Laura Johnson in preparing this text.

\section{References}

1. Oerke, E.C.; Dehne, H.W.; Schönbeck, F.; Weber, A. Crop production and crop protection-Estimated losses in major food and cash crops. Agric. Syst. 1996, 51, 493-495.

2. Juma, C. The New Harvest, Agricultural Innovation in Africa; Oxford University Press: Oxford, UK, 2010.

3. Aerni, P. Exploring the Linkages of commerce, higher education and human development: A historical review. ADTF J. 2007, 4, 35-47.

4. Drayton, B.; Budinich, V. A new alliance for global change. Harvard Business Review, September 2010. Available online: http://hbr.org/2010/09/a-new-alliance-for-global-change/ar/1 (accessed on 17 June 2011).

5. Braun, H. Wheat Rust; CIMMYT: Mexico. Available online: http://www.syngentafoundation.org/ index.cfm?pageID=691 (accessed on 17 June 2011).

6. The G-20 Toronto Summit Declaration. In Proceedings of the G20 Summit, Toronto, Canada, June 2010; pp. 1-27.

7. Beintema, N.; Elliott, H. Setting Meaningful Investment Targets in Agricultural Research and Development: Challenges, Opportunities and Fiscal Realities. Presented at Expert Meeting on How to Feed the World in 2050-Food and Agriculture Organization of the United Nations, Rome, Italy, June 2009.

8. Pardey, P.G. Putting U.S. Agricultural R\&D and Productivity Developments in Perspective. Presented at the Farm Foundation Conference, Washington, DC, USA, April 2009.

9. Bartel, C.; Tadele, Z.; Paterson A.; Bhattacharjee, R.; Gedil, M.; Esfeld, K.; Dubois, T.; Plaza, S.; Lambein, F.; Dominique, D. African orphan crops: Their significance and prospects for improvement. ADTF J. 2009, 6, 1-82.

10. Ferroni, M. Can Private-Sector R\&D Reach Small Farms? In World Food Security: Can Private Sector R\&D Feed the Poor? In Proceedings of The Crawford Fund 15th Annual International Conference, Canberra, Australia, 28-29 October 2009; Brown, A.G., Eds.; 2009; AGRA: Nairobi, Kenya, pp. 3-12.

11. Dorosh, P.; Schmidt, E. The Rural-Urban Transformation in Ethiopia. Ethiopia Strategy Support Program 2 (ESSP2) Working Paper 13. International Food Policy Research Institute (IFPRI): Addis, Ethiopia, June 2010. Available online: http://www.ifpri.org/sites/default/files/publications/ esspwp013.pdf (accessed on 15 November 2010).

12. Spaenij-Dekking, L.; Kooy-Winkelaar, Y.; Koning, F. The Ethiopian cereal tef in celiac disease. N. Engl. J. Med. 2005, 353, 1748-1749. 
13. FAOSTAT. Production, Crops, 2009. Food and Agricultural Organization of the United Nations (FAO). Available online: http://faostat.fao.org/site/567/default.aspx\#ancor (accessed on 15 November 2010).

14. Dixon, J.; Braun, H.-J.; Kosina, P.; Crouch, J. Wheat Facts and Futures 2009; CIMMYT: Batan, Mexico, 2009.

15. Paisner, M.S.; Meijer, S.; Rosegrant, M.W.; Witcover, J. Global Food Projections to 2020: Emerging Trends and Alternative Futures; International Food Policy Research Institute: Washington, DC, USA, 2001.

16. Goslinga, R. Personal communication based on project partners' combined data, November 2010.

17. Ferroni, M. Harnessing Private and Public Investment for Enhanced Productivity in Smallholder Agriculture. Presented at the 2008 Annual Meetings Program of Seminars-World Bank; Washington, DC, USA, October 2008.

18. Von Braun, J.; Ferroni, M. Public-Private Partnerships in Agriculture Research: Towards Best Practice and Replicable Models; The World Bank: Washington, DC, USA, 2008. Available online: http://www.syngentafoundation.org/db/1/570.pdf (accessed on 15 November 2010).

(C) 2011 by the authors; licensee MDPI, Basel, Switzerland. This article is an open access article distributed under the terms and conditions of the Creative Commons Attribution license (http://creativecommons.org/licenses/by/3.0/). 